\title{
Prognosis of breast cancer molecular subtypes in routine clinical care: A large prospective cohort study
}

\author{
André Hennigs ${ }^{1}$, Fabian Riedel ${ }^{1}$, Adam Gondos ${ }^{2}$, Peter Sinn ${ }^{3}$, Peter Schirmacher ${ }^{3}$, Frederik Marmé ${ }^{1,4}$, Dirk Jäger ${ }^{4}$, \\ Hans-Ulrich Kauczor ${ }^{5}$, Anne Stieber ${ }^{5}$, Katja Lindel ${ }^{5}$, Jürgen Debus ${ }^{5}$, Michael Golatta ${ }^{1}$, Florian Schütz ${ }^{1}$, Christof Sohn ${ }^{1}$, \\ Jörg Heil ${ }^{1 *+}$ and Andreas Schneeweiss ${ }^{6+}$
}

\begin{abstract}
Background: In Germany, most breast cancer patients are treated in specialized breast cancer units (BCU), which are certified, and routinely monitored. Herein, we evaluate up-to-date oncological outcome of breast cancer (BC) molecular subtypes in routine clinical care of a specialized BCU.

Methods: The study was a prospectively single-center cohort study of 4102 female cases with primary, unilateral, non-metastatic breast cancer treated between 01 January 2003 and 31 December 2012. The five routinely used molecular subtypes (Luminal A-like, Luminal B/HER2 negative-like, Luminal B/HER2 positive-like, HER2-type, Triple negative) were analyzed. The median follow-up time of the whole cohort was 55 months. We calculated estimates for local control rate (LCR), disease-free survival (DFS), distant disease-free survival (DDFS), overall survival (OS), and relative overall survival (ROS).

Results: Luminal A-like tumors were the most frequent (44.7\%) and showed the best outcome with LCR of $99.1 \%$ ( $95 \%$ Cl 98.5; 99.7), OS of $95.1 \%$ (95 \% Cl 93.7; 96.5), and ROS of $100.0 \%$ (95 \% Cl 98.5; 101.5). Triple negative tumors (12.3\%) presented the poorest outcome with LCR of $89.6 \%$ (95 \% Cl 85.8; 93.4), OS of $78.5 \%$ (95\% Cl 73.8; 83.3), and ROS of $80.1 \%(95 \% \mathrm{Cl} 73.8 ; 83.2)$.

Conclusions: Patients with a favorable subtype can expect an OS above $95 \%$ and an LCR of almost $100 \%$ over 5 years. On the other hand the outcome of patients with HER2 and Triple negative subtypes remains poor, thus necessitating more intensified research and care.
\end{abstract}

Keywords: Breast cancer, Molecular subtypes, Outcome, Breast care unit

\section{Background}

Breast cancer $(\mathrm{BC})$ mortality has declined over the past decade in most developed countries, due to new developments in screening, diagnostics, surgery, radiotherapy, and (neo) adjuvant systemic therapy, in conjunction with structural improvements (multidisciplinarity, implementation of specialized breast cancer units) and target agreements (evidence-based guidelines, certification processes) $[1,2]$. Over the past

\footnotetext{
* Correspondence: joerg.heil@med.uni-heidelberg.de

${ }^{\dagger}$ Equal contributors

${ }^{1}$ Department of Gynecology and Obstetrics, University of Heidelberg, Im

Neuenheimer Feld 440, 69120 Heidelberg, Germany

Full list of author information is available at the end of the article
}

decade, increasing molecular and genetic knowledge [3-6] has provided a new understanding of breast cancer as a heterogeneous, systemic disease that can be classified into different subtypes with different clinical and pathological features, different therapeutic response patterns, and different outcomes [7, 8]. The main molecular classification of breast cancer have been distinguished by gene expression profiling into intrinsic subtypes by Peru et at [5]. These modern microarray-based gene expression profiles (GEP) are the best way to visualize the heterogeneity of breast cancer, but lacking gene expression profiling in clinical 
routine due to cost and practicability made a surrogate classification necessary [9]. The molecular subtypes of breast cancer correspond reasonably well to a clinical characterization on the basis of hormone-and HER2 status, as well as proliferation markers or histological grade [10]. So the classification based on immunohistochemistry (IHC) markers was recommended by the St. Gallen Expert Consensus in 2011 [11] and confirmed again in 2013 [12]. It has become the accepted standard in routine clinical patient care. Classification into five molecular subtypes (Luminal A-like, Luminal B/HER2 negative-like, Luminal B/HER2 positive-like, HER2-type, Triple negative) helps to sort patients into groups with divergent prognoses and different response patterns to specific Every-day-routine outcome assessment of specialized breast cancer unit (BCU) must validate guideline-based care of $\mathrm{BC}$ patients in order to optimize the therapy of every individual case. This paper reports the outcome data of a prospective cohort of 4102 patients with primary, unilateral, non-metastatic $\mathrm{BC}$ treated at a specialized BCU according to routinely used molecular subtype definitions based on immunohistochemistry markers.

\section{Methods}

\section{Patients}

Since 01 January 2003 the medical history and the demographic, diagnostic, therapeutic, and follow-up data of all breast cancer patients referred to the $\mathrm{BCU}$ at Heidelberg University have been prospectively entered into our database. This register is routinely used for certification purposes and is monitored.

Patients from the registry were included in the present analysis if they had invasive or carcinoma-in-situ cancer of the breast and were newly diagnosed or treated between 01 January 2003 and 31 December 2012.

Patients were excluded from this analysis for any of the following reasons: male sex $(n=38)$, distant metastasis at the intake visit (M1, $n=296)$ or bilateral tumors $(n=619)$.

Patients with incomplete immunohistological information (149, i.e. $4.1 \%$ of 3603$)$ were included in the overall analysis, but they could not be considered in the subgroup outcome analysis.

\section{Histology and stage}

Tumors were defined according to the World Health Organization [13], graded along Elston and Ellis [14], and grouped into stages according to the TNM classification [15]. The expression of estrogen receptor (ER), progesterone receptor (PR), human epidermal growth factor receptor 2 (HER2), and Ki-67 were assessed with an IHC assay of formalin-fixed, paraffin-embedded tumor tissue according to international standards.

\section{Subgroups}

According to the St. Gallen International Expert Consensus recommendations 2011 [11], five molecular subtypes of invasive breast cancer have been differentiated by their expression of the IHC markers ER, PR, HER2, and Ki-67:

\begin{tabular}{lllll}
\hline Intrinsic suptype & & ER and/or PR & HER2 & Ki-67 \\
Luminal A-like & (LumA) & + & - & $<14 \%$ \\
Luminal B/HER2 & (LumB/HER2 neg.) & + & - & $\geq 14 \%$ \\
negative-like & & & & \\
$\begin{array}{l}\text { Luminal B/HER2 } \\
\text { positive-like }\end{array}$ & (LumB/HER2 pos.) & + & + & any \\
HER2-type & $($ HER2) & both- & + & any \\
Triple negative & (TN) & both- & - & any \\
\hline
\end{tabular}

The classification of 2011 was used because it corresponded best to the way we had categorized patients during the time period covered in this report [11].

Positivity for ER and PR was defined as an Immunoreactive Score [16] of at least 1 out of 12 or a Total Score [17] of at least 1 out of 8 . All cases of non-invasive carcinomain-situ (CIS, regardless of specific subtype) have been defined as an additional subgroup for a separate analysis.

For invasive $\mathrm{BC}$, the cell proliferation marker Ki-67 was available in the majority of our cohort (3004/3603, $83.4 \%$ ), while grading, either 1 or 3 , was used in 599 of the 3603 cases (16.6\%) for subgroup classification (Table 1). For the differentiation of Luminal-like tumors, cases with a negative HER2 receptor status in combination with a positive ER or PR receptor and a grading of 1 led to the attribution of the Luminal A-like subgroup. In contrast a grading of G3 was assigned to the subgroup of Luminal B/HER2 negative-like tumors.

\section{Treatment}

The Heidelberg University BCU was fully certified on 10 October 2003, by the German certification board of the German Cancer Society and the German Society for Senology on the basis of the management of cases in 2002 and 2003. Thus all the cases included in this study were managed under certified conditions, which were confirmed by an annual re-certification process $[18,19]$.

\section{Endpoints and outcome assessment}

The outcome from the time of diagnosis was assessed for the whole cohort, the five BC subtypes, and the CIS cases for several outcome parameters. The endpoints were local control rate (LCR), disease-free survival (DFS), distant disease-free survival (DDFS), overall survival (OS), and relative overall survival (ROS). Relative survival was 
Table 1 Patient, tumor, and surgical therapy characteristics of all female cases with primary, non-metastatic, unilateral breast cancer diagnosed at the Heidelberg Breast Care Unit between 01 January 2003 and 31 December 2012

\begin{tabular}{|c|c|c|}
\hline Total cases $(n=4102)$ & Number of cases & Percent (\%) \\
\hline
\end{tabular}

Age at diagnosis in years $(n=4102)$

$\begin{array}{lll}\text { median } & 57 \text { years } & \\ <51 & 1355 & 33.0 \\ 51-65 & 1638 & 39.9 \\ >65 & 1109 & 27.0 \\ \text { total } & 4102 & 100.0\end{array}$

Menopausal status $(n=4102)$

pre
peri
post
missing
total

Affected breast $(n=4102)$

left

right

1377

33.6

130

2498

97

4102

2066

2036

total

Tumor characteristics

Main tumor histology ( $n=4102)$

In-situ Carcinoma
Invasive Carcinoma
Invasive ductal carcinoma
(no specific type)
Invasive lobular carcinoma
other (e.g. invasive medullar/mixed)
total

stage for invasive cases with adjuvant therapy $(n=2997)$

$$
\text { pT1 }
$$

pT1a

pT1b

pT1c

pTmic

unknown

pT2

pT3

pT4

$\mathrm{p} T \mathrm{x} / \mathrm{missing}$

total

T stage for invasive cases with neoadjuvant therapy $(n=606)$

ypT0

ypTis
499

3603

3082

481

40

4102

1863

161

486

1202

7

7

909

138

58

29

2997

16
Table 1 Patient, tumor, and surgical therapy characteristics of all female cases with primary, non-metastatic, unilateral breast cancer diagnosed at the Heidelberg Breast Care Unit between 01 January 2003 and 31 December 2012 (Continued)

\begin{tabular}{|c|c|c|}
\hline ypT1 & 224 & 37.0 \\
\hline ypT1a & 47 & \\
\hline ypT1b & 52 & \\
\hline ypT1c & 115 & \\
\hline ypTmic & 8 & \\
\hline unknown & 2 & \\
\hline ypT2 & 127 & 21.0 \\
\hline урт3 & 47 & 7.8 \\
\hline ypT4 & 16 & 2.6 \\
\hline ypTx/missing & 8 & 1.3 \\
\hline total & 606 & 100.0 \\
\hline \multicolumn{3}{|c|}{ N stage for invasive cases $(n=3603)$} \\
\hline pNO & 2473 & 68.6 \\
\hline pN1 & 655 & 18.2 \\
\hline pN2 & 243 & 6.7 \\
\hline pN3 & 158 & 4.4 \\
\hline $\mathrm{pNx} / \mathrm{missing}$ & 74 & 2.1 \\
\hline total & 3603 & 100.0 \\
\hline \multicolumn{3}{|c|}{ Grading (invasive cases, $n=3603$ ) } \\
\hline Grade 1 & 600 & 16.7 \\
\hline Grade 2 & 1924 & 53.4 \\
\hline Grade 3 & 962 & 26.7 \\
\hline missing & 117 & 3.2 \\
\hline total & 3603 & 100.0 \\
\hline \multicolumn{3}{|c|}{$\begin{array}{l}\text { Estrogen receptor } \\
\text { (invasive cases, } n=3603 \text { ) }\end{array}$} \\
\hline positive & 2877 & 79.9 \\
\hline negative & 585 & 16.2 \\
\hline missing & 141 & 3.9 \\
\hline total & 3603 & 100.0 \\
\hline \multicolumn{3}{|c|}{$\begin{array}{l}\text { Progesterone receptor } \\
\text { (invasive cases, } n=3603 \text { ) }\end{array}$} \\
\hline positive & 2599 & 72.1 \\
\hline negative & 859 & 23.8 \\
\hline missing & 145 & 4.0 \\
\hline total & 3603 & 100.0 \\
\hline \multicolumn{3}{|c|}{$\begin{array}{l}\text { HER2 receptor } \\
\text { (invasive cases, } n=3603 \text { ) }\end{array}$} \\
\hline positive & 346 & 9.6 \\
\hline negative & 3118 & 86.5 \\
\hline missing & 139 & 3.9 \\
\hline total & 3603 & 100.0 \\
\hline
\end{tabular}

Ki-67 status

(invasive cases, $n=3603$ ) 
Table 1 Patient, tumor, and surgical therapy characteristics of all female cases with primary, non-metastatic, unilateral breast cancer diagnosed at the Heidelberg Breast Care Unit between 01 January 2003 and 31 December 2012 (Continued)

\begin{tabular}{lll}
\hline$<14 \%$ & 1463 & 40.6 \\
$\geq 14 \%$ & 1541 & 42.8 \\
missing & 599 & 16.6 \\
total & 3603 & 100.0 \\
Surgical therapy characteristics & & \\
Surgical therapy ( $n=4102)$ & & \\
Breast Conserving Surgery & 2999 & 73.1 \\
Mastectomy & 1103 & 26.9 \\
total & 4102 & 100.0 \\
Axillary staging $(n=4102)$ & & \\
SLND only & 1671 & 40.7 \\
SLND + ALND & 501 & 12.2 \\
ALND only & 1600 & 39.0 \\
none & 330 & 8.1 \\
total & 4102 & 100.0 \\
\hline
\end{tabular}

SLND sentinel lymphadenectomy, ALND axillary lymphadenectomy

defined as the ratio of the observed survival to the survival expected in the general West German population of the same age and sex during the same period of time [20].

Outcome was assessed as follows. First, hospital records were reviewed to obtain information with regard to survival, local and regional relapse, and distant metastasis. If outcome information was not available in the hospital record, the patient's family doctor or gynecologist was contacted by mail or phone. If the required information could not be obtained by this approach either, an inquiry about the patient's survival status was made at the responsible residents' registration office. If the patient was still alive, she was contacted by mail and asked whether she had developed local or distant relapse with a detailed questionnaire. Follow-up was performed for cases diagnosed until 31 December 2012. Within this study period (starting 01 January 2003) $n=2322$ patients had a complete follow-up information (i.e. could be followed until either death or study end. Of the remaining 1780 patients, 140 were lost to follow-up during the years 2003-2011, i.e. in total 140/4102 (3.4 \%). The median time of follow-up was 45 months among those who were lost to follow-up, slightly shorter than among the whole cohort (55 months).

\section{Statistical analysis}

The data were analyzed using SAS software version 9.3 (SAS Institute Inc.; Cary, NC, USA) and SPSS software version 22 (IBM; Armonk, NY, USA). The proportions of patients experiencing events at 5 years, the corresponding $95 \%$ confidence intervals (95\% CI), and all survival plots are based on Kaplan-Meier estimates using PROC LIFETEST with the actuarial approach. Relative survival rates at 5 years were also calculated. The expected survival of the general population was calculated according to the Ederer II method [21], based on life tables for Germany for the years 2002 to 2010 .

\section{Results}

\section{Patient characteristics}

The final cohort comprised 4102 patients, of which, 3603 $(87.8 \%)$ had invasive carcinoma and 499 (12.2\%) had CIS. Most invasive carcinoma cases were hormone receptor positive (ER: $79.9 \%$, PR: $72.1 \%$ ), HER2 negative $(86.5 \%)$, and had a grading of $2(53.4 \%)$. Most of the patients had a maximum tumor size of $2 \mathrm{~cm}$ (pT1: 62.2\%) without axillary lymph node involvement (pN0 $68.6 \%$ ). Median age of the whole cohort was 57 years and most patients were postmenopausal (60.9 \%). Breast conservation surgery was performed in $73.1 \%$ of the study cohort and a mastectomy in $26.9 \%$. Concerning surgical management of the axilla sentinel lymph node biopsy alone (SLND) was performed in $40.7 \%$ and axillary lymph node dissection in $39.0 \%$ of the patients. Detailed patient characteristics of the cohort are shown in Table 1.

The UICC stage distribution (Additional file 1: Table S4) as well as the frequency of age, menopausal status and laterality (Additional file 2: Table S5) for the different subtypes can be found in the supplementary material.

\section{Outcome analysis}

For all patients with invasive disease, LCR was $96.1 \%$ (95\% CI 95.3; 96.9); DFS was $83.7 \%$ (95 \% CI 82.2; 85.2); DDFS was $85.7 \%$ (95\% CI 84.3; 87.1); OS was $90.5 \%$ (95 \% CI 89.3; 91.7) and ROS was $97.7 \%$ (95\% CI $93.4 ; 96.0)$ at 5 years. As regards cancer subtypes, $44.7 \%$ were luminal A-like, $31.8 \%$ Luminal B/HER2 negative-like, $6.2 \%$ Luminal B/HER2 positive-like, $5.0 \%$ HER2-type, and $12.3 \%$ Triple negative. The Luminal Alike subtype showed the best outcome: LCR was $99.1 \%$ (95 \% CI 98.5; 99.7); DFS was 92.1 (95\% CI 90.5; 93.9); DDFS was $92.9 \%$ (95 \% CI 91.3; 94.5); OS was $95.1 \%$ (95\% CI 93.7; 96.5) and ROS was $100.0 \%$ (95 \% CI 98.5; 101.5). The Triple negative subtype had the worst outcome: LCR at 5 years was $89.6 \%$ (95 \% CI 85.8; 93.4); DFS was $69.1 \%$ (95 \% CI 64.1; 74.1); DDFS was $72.2 \%$ (95 \% CI 67.3; 77.1); OS was $78.5 \%$ (95 \% CI 73.8; 83.2); and ROS was $80.1 \%$ (95\% CI 75.1; 85.1). Outcome measures for the whole cohort, with or without inclusion of CIS cases, and for all clinico-pathological subtypes at 5 years are presented in Tables 2 and 3. The corresponding Kaplan-Meier plots are shown in Figs. 1 and 2. 
Table 2 Five-year outcomes of 5 different endpoints for all female patients with primary, non-metastatic, unilateral breast cancer treated at the Heidelberg Breast Care Unit between 01 January 2003 and 31 December 2012

\begin{tabular}{lll}
\hline & $\begin{array}{l}\text { All patients (including in-situ) } \\
n=4102 \text { (including } 499 \text { in-situ cases) }\end{array}$ & $\begin{array}{l}\text { Patients with invasive cancer } \\
\text { (excluding in-situ) } n=3603\end{array}$ \\
\hline LCR [\%] $(95 \% \mathrm{Cl})$ & $96.1(95.3 ; 96.9)$ & $96.1(95.3 ; 96.9)$ \\
DFS [\%] $(95 \% \mathrm{Cl})$ & $84.9(83.6 ; 86.2)$ & $83.7(82.2 ; 85.2)$ \\
DDFS [\%] $(95 \% \mathrm{Cl})$ & $86.9(85.7 ; 88.1)$ & $85.7(84.3 ; 87.1)$ \\
OS [\%] $(95 \% \mathrm{Cl})$ & $91.3(90.2 ; 92.4)$ & $90.5(89.3 ; 91.7)$ \\
ROS [\%] $(95 \% \mathrm{Cl})$ & $95.5(94.3 ; 96.7)$ & $94.7(93.4 ; 96.0)$ \\
\hline
\end{tabular}

Cl confidence interval, $L C R$ local recurrence rate, DFS disease-free survival, DDFS distant disease-free survival, OS observed overall survival, ROS relative overall survival

Additional outcome analyses for subtypes subdivided into UICC stages I-IIa (Additional file 3: Table S6) can be found in the supplementary material.

\section{Discussion}

The 5-year OS for all patients with primary invasive breast cancer was $90.5 \%$ (95 \% CI 89.3; 91.7), and the ROS was 94.7 \% (95 \% CI 93.4; 96.0) (Table 2). This confirms the favorable prognosis of primary non-metastatic breast cancer receiving adequate treatment. In this study, we focused on a well-defined and homogenous patient cohort. The outcomes seen here can be expected at any specialized BCU. Most of the outcomes statistics published in the literature derive from clinical trials with the exclusion of certain types of patients commonly seen in routine care, e.g. the elderly patients with comorbid conditions. Thus, it is important to assess outcomes among a complete, unselected patient population seen in a routine clinical setting. On the basis of the favorable outcome results reported here, additional quality-of-life aspects might be brought more into focus for outcome quality for specific subgroups in the future.

In the face of unavailable gene expression profiles in clinical routine, the $\mathrm{BC}$ surrogate classification according to the St. Gallen Consensus 2011 [11] allows a differentiation of five molecular subtypes with distinct prognoses. Although the management of $\mathrm{BC}$ patients according to these subtypes has gained importance, it is beyond controversy that the traditionally assessed tumor characteristics, e.g. nodal status and tumor size, still have independent prognostic impact [22]. Because the St. Gallen subtype classification is widely accepted as a surrogate for subtyping according to intrinsic signatures [9], we used this classification for subtype-specific outcome analysis as they are distinct and well applicable in the context of outcome assessment. Standard pathological assessments seem adequate to define useful groups such as TN, HER2-type, and LumB/HER2 pos.-like tumors, for which treatment recommendations are seldom controversial [23]. In contrast to other studies (e.g. [24]), the Ki-67 score was available for the vast majority of cases, enabling us to differentiate the Luminal-like HER2 negative tumors. Nevertheless, the validity and robustness of Ki-67 is still controversial, although it has been widely accepted as a cell proliferation marker that is widely available [25]. Especially the St. Gallen 2011 cut-off recommendation of $14 \%$ for Ki-67 (which was proposed and validated by

Table 3 Outcome results of 5 different endpoints for all female cases with primary, non-metastatic, unilateral breast cancer treated at the Heidelberg Breast Care Unit between 01 January 2003 and 31 December 2012, (for whom all necessary histological information were available for distinct subtype attribution), differentiated by the invasive clinico-pathological tumor subtype or in-situ tumor (CIS). Results in percent at 5 years $(95 \% \mathrm{Cl})$

\begin{tabular}{|c|c|c|c|c|c|c|}
\hline & \multicolumn{5}{|c|}{ INVASIVE CANCER } & \multirow{5}{*}{$\begin{array}{l}\text { CIS } \\
n=499 \\
(100 \%)\end{array}$} \\
\hline & LumA-like & $\begin{array}{l}\text { LumB/HER2 } \\
\text { neg.-like }\end{array}$ & $\begin{array}{l}\text { LumB/HER2 } \\
\text { pos.-like }\end{array}$ & HER2-type & $\begin{array}{l}\text { Triple } \\
\text { negative }\end{array}$ & \\
\hline & \multicolumn{5}{|c|}{$\begin{array}{l}\qquad n=3454 \text { (100 \%) } \\
\text { [missing due failed distinct subtype distribution } n=149 \text {, i.e. } 4.1 \% \text { of invasive cohort] }\end{array}$} & \\
\hline & $n=1545$ & $n=1099$ & $n=215$ & $n=171$ & $n=424$ & \\
\hline & $44.7 \%$ & $31.8 \%$ & $6.2 \%$ & $5.0 \%$ & $12.3 \%$ & \\
\hline LCR [\%] (95 \% Cl) & $99.1(98.5 ; 99.7)$ & $95.2(93.6 ; 96.8)$ & $95.0(91.3 ; 98.7)$ & $90.5(84.7 ; 96.3)$ & $89.6(85.8 ; 93.4)$ & $96.2(93.9 ; 98.5)$ \\
\hline DFS [\%] (95 \% Cl) & $92.2(90.5 ; 93.9)$ & $80.1(77.2 ; 83.0)$ & $79.0(71.9 ; 86.1)$ & $77.0(69.4 ; 84.6)$ & $69.1(64.1 ; 74.1)$ & $93.0(90.2 ; 95.8)$ \\
\hline DDFS [\%] $(95 \% \mathrm{Cl})$ & $92.9(91.3 ; 94.5)$ & $82.2(79.5 ; 84.9)$ & $82.8(76.0 ; 89.6)$ & $83.3(76.6 ; 90.0)$ & $72.2(67.3 ; 77.1)$ & $95.6(93.5 ; 97.1)$ \\
\hline OS [\%] (95 \% Cl) & $95.1(93.7 ; 96.5)$ & $88.7(86.2 ; 91.2)$ & $92.5(87.9 ; 97.1)$ & $85.6(78.6 ; 92.6)$ & $78.5(73.8 ; 83.2)$ & 96.9 (94.8; 99.0) \\
\hline ROS [\%] $(95 \%$ Cl) & $100.0(98.5 ; 101.5)$ & $93.4(90.7 ; 96.1)$ & $96.0(91.2 ; 100.8)$ & $88.8(81.5 ; 96.1)$ & $80.1(75.1 ; 85.1)$ & $100.8(98.6 ; 103.0)$ \\
\hline
\end{tabular}

Cl confidence interval, $L C R$ local recurrence rate, DFS disease-free survival, DDFS distant disease-free survival, OS observed overall survival, $R O S$ relative overall survival, CIS carcinoma-in-situ 


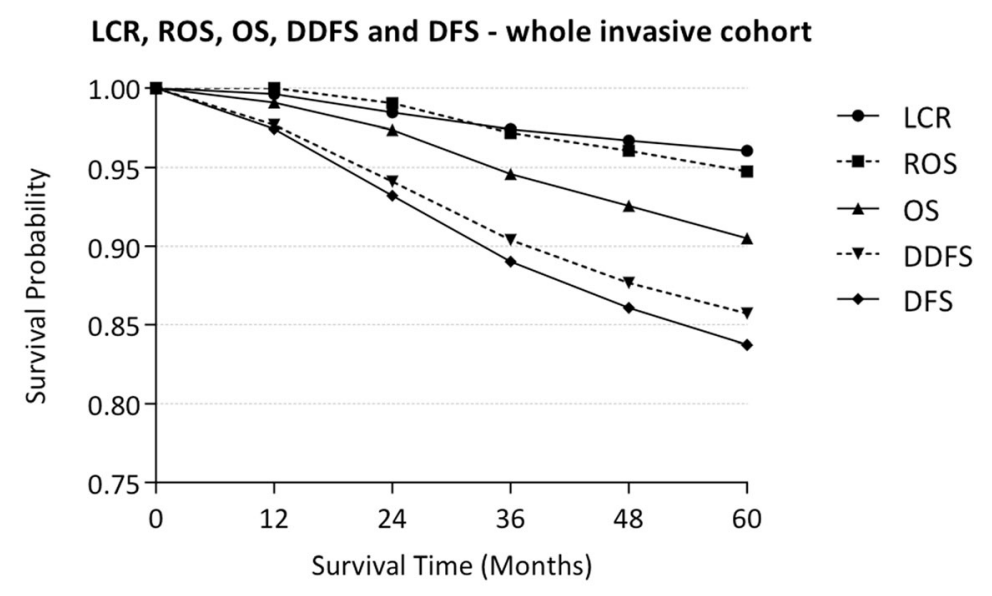

\begin{tabular}{lcccccc}
\multicolumn{6}{l}{ effective sample size } \\
& $\mathbf{0}$ & $\mathbf{1 2}$ & $\mathbf{2 4}$ & $\mathbf{3 6}$ & $\mathbf{4 8}$ & $\mathbf{6 0}$ \\
LCR & 3603 & 3078 & 2717 & 2212 & 1788 & 1378 \\
ROS & 3603 & 3324 & 2796 & 2345 & 1923 & 1527 \\
OS & 3603 & 3324 & 2794 & 2344 & 1921 & 1525 \\
DDFS & 3603 & 3407 & 2914 & 2404 & 1965 & 1536 \\
DFS & 3603 & 3407 & 2908 & 2383 & 1937 & 1509
\end{tabular}

Fig. 1 LCR, ROS, OS, DDFS and DFS-whole invasive cohort. Kaplan-Meier survival plot for LCR, ROS, OS, DDFS, and DFS for the cohort of invasive cases. Shown are annual survival rates. The table presents the effective sample size for each interval. [LCR: local recurrence rate; DFS: disease-free survival; DDFS: distant disease-free survival; OS: observed overall survival; ROS: relative overall survival]

Cheang et al. [26]) has been viewed critically due to a substantial inter-observer and intra-observer variability, especially for mid-range Ki-67 scores [27-29]. This discordance is highly problematic because a recommendation for or against chemotherapy for hormone receptor positive, HER 2 negative, grade 2 tumors depends mainly on the Ki-67 threshold in the St. Gallen Consensus 2011.

Because of this ambiguity in defining exact surrogate subtypes it might be difficult to compare subtype outcome results with other studies that used different surrogate definitions. Despite this difficulty in comparison with other study designs the general trend concerning distribution (at least for clear defined subtypes like $\mathrm{TN}$ ) and outcome in our cohort is in approximate accordance with other results e.g. from Canada [30], USA [31, 32], South Korea [33], Belgium [24], Spain [34, 35], Italy [36] and France [37]: LumA and LumB tumors were the most frequent (LumA was $44.7 \%$, LumB/HER2 neg. was $31.8 \%$, and LumB/HER2 pos. was $6.2 \%$ ), followed by TN cancers (12.3\%) and HER2 type (5.0 \%). For the majority of patients with a Luminal A type a very favorable OS over 5 years of $95.1 \%$ (95\% CI 93.7; 95.5) and an excellent LCR of $99.1 \%$ (95 \% CI 98.5; 99.7) was possible. But it becomes also evident that outcome possibilities for HER-2 type and TN cases are still much poorer even in times of more effective systemic treatment (Table 3). Two exemplary studies with large cohorts-the single-hospital report from Broukhaert et al. in Belgium [24] and the population-based report from Minicozzi et al. in Italy [36]-both used similar criteria approximating the St. Gallen 2011 classification. These two studies had quite comparable distributions of BC subtypes (42\% and $56 \%$ for LumA-like, $27 \%$ and $22 \%$ for LumB/HER2 neg.-like, $14 \%$ and $7 \%$ for LumB/ HER2 pos.-like, $7 \%$ and $4 \%$ for HER2-type, and $11 \%$ and $10 \%$ for TN). And these two studies also found similar outcomes; the DFS over 5 years was $93.0 \%$ and $94.6 \%$ for LumA-like, $87.4 \%$ and $85.7 \%$ for Lum B/HER2 neg.like, $86.3 \%$ and $86.8 \%$ for LumB/HER2 pos.-like, $77.9 \%$ and $79.7 \%$ for HER2-type, and $80.5 \%$ and $81.0 \%$ for TN. DFS was somewhat lower for LumB-like and TN in our cohort than in those two other studies. Besides slightly different subtype and endpoint definitions, it must be considered that Broukhaert et al. used tumor grade instead of Ki-67 for defining subtypes, (with the associated problems mentioned above), and Minicozzi et al. studied a retrospective cohort (2003-2005) with a different Ki-67 cut-off and lack of reliable information about how Ki-67 was determined at that time.

In our cohort the median age of early breast cancer patients was 57 years compared to 64 years in Germany. Concerning surgical procedures mastectomy was performed in $26.9 \%$ of all patients, which is lower than in a current published report from the SEER database with a mastectomy rate of $34 \%$ showing an increase in the United States especially in women with node-negative 


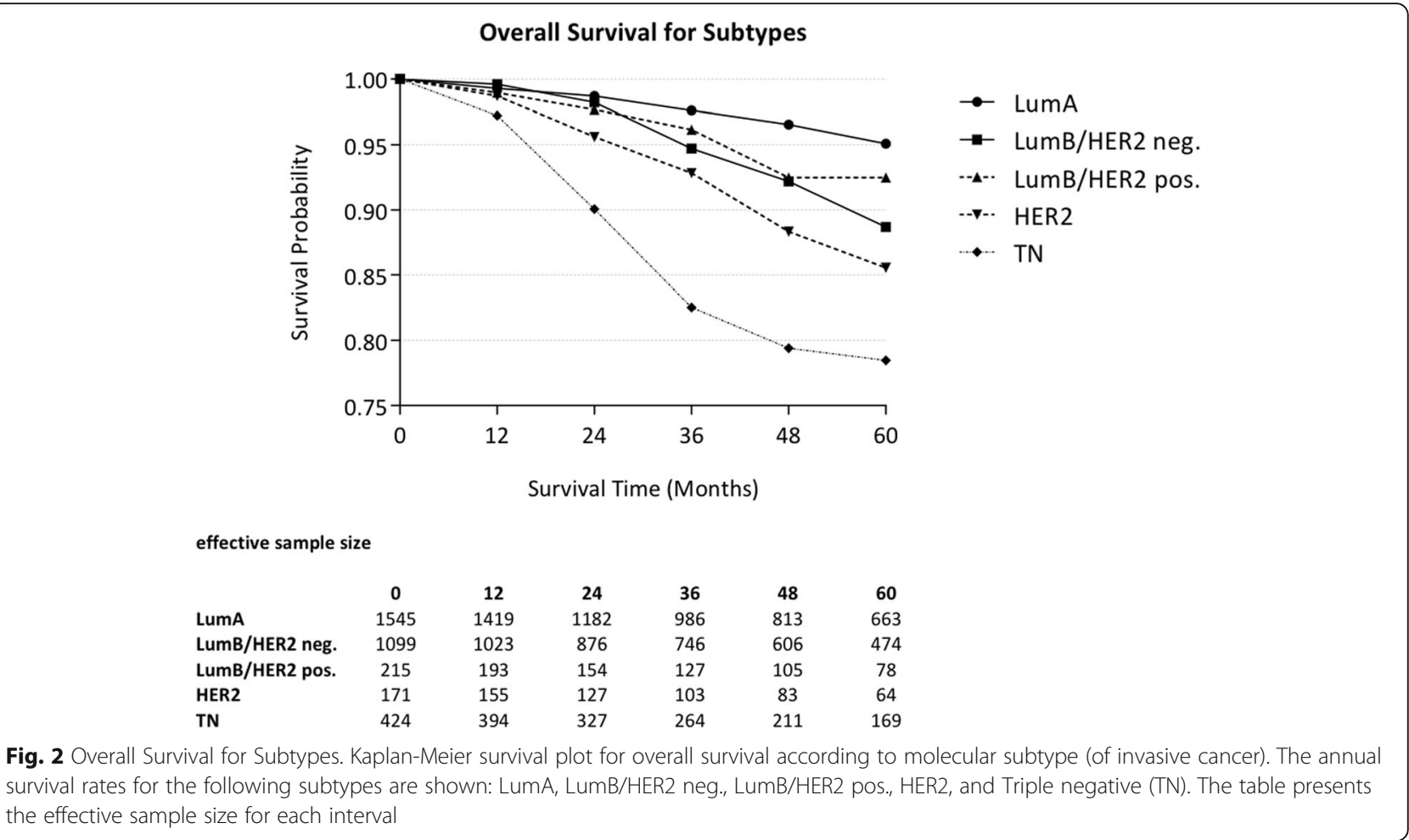

and in-situ disease (Table 1) [38]. The widely use of specific anti-HER2 therapy in this cohort could increase outcome for patients with HER2 positive breast cancer [39]. The subgroup of patients with Luminal B/HER2 positive-like reveals a LCR of $95.0 \%$ (95\% CI 91.3; 98.7) and a ROS of $93.4 \%(95 \%$ CI $91.2 ; 100.8)$ at 5 years. Note, however, that the HER2-type subgroup had the second poorest outcome with a LCR of $90.5 \%(95 \% \mathrm{CI}$ 84.7 ; 96.3) and a ROS of $88.8 \%$ (95 \% CI 81.5; 96.1) (Table 3 ). The poor survival of triple-negative tumors reflects the lack of effective and specific therapy for this subgroup of patients.

\section{Strengths and limitations}

This study adds recent up-to-date outcomes for the 5 different molecular subtypes from a large prospective cohort with a broad usage of Ki-67 for subtype definition (with a cut-off at $14 \%$ ). Unfortunately the subgroups in this study are too small with a favorable outcome and the analysis is underpowered to exhibit further differences in stage distribution as well as surgical and systemic management of primary breast cancer on outcome. The effective disentangling of these and further possible effect would require far larger sample sizes than are present in our data base, and should be pursued within cooperative research projects [40].

In our study, the cohort mirrors the typical, unselected cohort of breast cancer patients treated at a specialized breast cancer unit, as there were no specific exclusion criteria. Unfortunately, we did not systematically document a performance status describing comorbidities. As a prospective, single center study, we cannot exclude any potential center effects that may have confounded the results. Further outcome studies from other clinical settings may help to identify if and to what extent outcomes may vary between different breast units.

\section{Conclusion}

If primary $\mathrm{BC}$ is managed at a specialized $\mathrm{BCU}$ under guideline-adherent conditions, patients with a favorable subtype can expect an OS above $95 \%$ and an LCR of almost $100 \%$ over 5 years. On the other hand the outcome of patients with HER2 and TN subtypes remains poor, thus necessitating more intensified research and care.

\section{Additional files}

Additional file 1: Table S4. Case frequency for subtypes along UICC stages for patients treated at Heidelberg Breast Care Unit between 01 January 2003, and 31 December 2012). (DOCX 18 kb)

Additional file 2: Table S5. Patient characteristics along breast cancer subtypes for patients diagnosed at Heidelberg Breast Care Unit between 01 January 2003 and 31 December 31 2012. (DOCX 17 kb)

Additional file 3: Table S6. Five-year Overall Survival exemplary for 3 Subtypes subdivided into UICC stages I and Ila for patients treated at Heidelberg Breast Care Unit between 01 January 2003 and 31 December 2012. (DOCX $15 \mathrm{~kb}$ ) 


\section{Abbreviations}

BC: Breast cancer; BCU: Breast cancer units; Cl: confidence interval; CIS: Carcinoma-in-situ; DDFS: Distant disease-free survival; DFS: Disease-free survival; ER: Estrogen receptor; GEP: Gene expression profiles; HER2: Human epidermal growth factor receptor 2; IHC: Immunohistochemistry; LCR: Local control rate; OS: Overall survival; PR: Progesterone receptor; ROS: Relative overall survival; UICC: Union Internationale contre le cancer

\section{Acknowledgements}

We would like to thank Michael Hanna, PhD, for proof-reading the manuscript and we would like to thank Christian Lange, Brigitte Wiegand and Ibrahim Kilic for the medical documentation and data management.

\section{Funding}

None

\section{Availability of data and materia}

The dataset analysed during the current study can be provided under special authorization from Prof. Schneeweiss, Heidelberg University Hospital, Division of Gynecological Oncology on reasonable request

\section{Authors' contributions}

$\mathrm{AH}, J \mathrm{H}$ and ASc designed the study, FR, AD conducted the statistical analysis, $\mathrm{AH}, \mathrm{JH}$ analyzed and interpreted the data, $\mathrm{AH}, \mathrm{JH}, \mathrm{H}-\mathrm{PS}, \mathrm{PS}, \mathrm{FM}, \mathrm{DJ} \mathrm{H}-\mathrm{UK}, \mathrm{ASt}$, $\mathrm{KL}, J \mathrm{D}, \mathrm{MG}, \mathrm{FS}, \mathrm{CS}, \mathrm{ASC}$ were involved in the data acquisition, $\mathrm{AH}, \mathrm{JH}$ wrote the manuscript, ASc, AG provide conceptual advice, All co-authors revised the manuscript and have given final approval for publication, JH takes final responsibility.

\section{Competing interests}

There are no conflicts of interests (e.g. employment, consultancies, stock ownership, honoraria, paid expert testimony, patent applications/registrations, or grants or other funding with regard to this study) for any of the authors.

\section{Consent for publication}

Not applicable.

\section{Ethics approval and consent to participate}

The study was approved by the ethics committee of the University of Heidelberg and in accordance with the Declaration of Helsinki. Because the study was deemed as without risk, including only anonymized analysis of routinely collected data, the ethics committee of the University of Heidelberg did not request approval for consent.

\section{Author details}

${ }^{1}$ Department of Gynecology and Obstetrics, University of Heidelberg, Im Neuenheimer Feld 440, 69120 Heidelberg, Germany. 'Division of Clinical Epidemiology and Aging Research, German Cancer Research Center (DKFZ) Im Neuenheimer Feld 581, 69120 Heidelberg, Germany. ${ }^{3}$ Department of Pathology, University of Heidelberg, Im Neuenheimer Feld 224, 69120 Heidelberg, Germany. ${ }^{4}$ National Center for Tumor Diseases (NCT), University Hospital, Im Neuenheimer Feld 460, 69120 Heidelberg, Germany. ${ }^{5}$ Radiology Department, University of Heidelberg, Im Neuenheimer Feld 400, 69120 Heidelberg, Germany. ${ }^{6}$ Department of Radiation Oncology, University of Heidelberg, Heidelberg, Germany.

\section{Received: 26 November 2015 Accepted: 6 September 2016} Published online: 15 September 2016

\section{References}

1. Desantis C, Ma J, Bryan L, Jemal A. Breast cancer statistics, 2013. CA Cancer J Clin. 2013;64(1):52-62.

2. Early Breast Cancer Trialists' Collaborative Group [EBCTCG]. Effects of chemotherapy and hormonal therapy for early breast cancer on recurrence and 15-year survival: an overview of the randomised trials. Lancet. 2005; 365(9472):1687-717

3. The Cancer Genome Atlas Network. Comprehensive molecular portraits of human breast tumours. Nature. 2012;490(7418):61-70.

4. Ellis MJ, Perou CM. The genomic landscape of breast cancer as a therapeutic roadmap. Can Discov. 2013;3(1):27-34.
5. Perou CM, Sorlie T, Eisen MB, van de Rijn M, Jeffrey SS, Rees CA, et al. Molecular portraits of human breast tumours. Nature. 2000;406(6797):747-52

6. Sorlie T, Perou CM, Tibshirani R, Aas T, Geisler S, Johnsen H, et al. Gene expression patterns of breast carcinomas distinguish tumor subclasses with clinical implications. Proc Natl Acad Sci U S A. 2001;98(19):10869-74.

7. Prat A, Perou CM. Deconstructing the molecular portraits of breast cancer. Mol Oncol. 2011;5(1):5-23.

8. Weigelt B, Baehner FL, Reis-Filho JS. The contribution of gene expression profiling to breast cancer classification, prognostication and prediction: a retrospective of the last decade. J Pathol. 2010;220(2):263-80.

9. Parker JS, Mullins M, Cheang MC, Leung S, Voduc D, Vickery T, et al. Supervised risk predictor of breast cancer based on intrinsic subtypes. J Clin Oncol Off Am Soc Clin Oncol. 2009;27(8):1160-7.

10. Sotiriou C, Pusztai L. Gene-expression signatures in breast cancer. N Engl J Med. 2009:360(8):790-800.

11. Goldhirsch A, Wood WC, Coates AS, Gelber RD, Thurlimann B, Senn HJ. Strategies for subtypes-dealing with the diversity of breast cancer: highlights of the St. Gallen International Expert Consensus on the Primary Therapy of Early Breast Cancer 2011. Ann Oncol. 2011;22(8):1736-47.

12. Goldhirsch A, Winer EP, Coates AS, Gelber RD, Piccart-Gebhart M, Thurlimann B, et al. Personalizing the treatment of women with early breast cancer: highlights of the St Gallen International Expert Consensus on the Primary Therapy of Early Breast Cancer 2013. Ann Oncol. 2013;24(9):2206-23.

13. Tavassoli FA. World Health Organization Classification of Tumours Pathology and genetics of tumours of the breast and female genital organs. Lyon: IARC Press; 2003.

14. Elston CW, Ellis IO. Pathological prognostic factors in breast cancer. I. The value of histological grade in breast cancer: experience from a large study with long-term follow-up. Histopathology. 1991;19(5):403-10.

15. Sobin LH, Gospodarowicz MK, Wittekind C. Cancer IUa. TNM classification of malignant tumours. 7th ed. New York: Wiley-Blackwell; 2009.

16. Remmele W, Stegner HE. Recommendation for uniform definition of an immunoreactive score (IRS) for immunohistochemical estrogen receptor detection (ER-ICA) in breast cancer tissue. Pathologe. 1987:8(3):138-40.

17. Harvey JM, Clark GM, Osborne CK, Allred DC. Estrogen receptor status by immunohistochemistry is superior to the ligand-binding assay for predicting response to adjuvant endocrine therapy in breast cancer. J Clin Oncol Off J Am Soc Clin Oncol. 1999:17(5):1474-81.

18. Beckmann MW, Brucker C, Hanf V, Rauh C, Bani MR, Knob S, et al. Quality assured health care in certified breast centers and improvement of the prognosis of breast cancer patients. Onkologie. 2011;34(7):362-7.

19. Brucker SY, Bamberg M, Jonat W, Beckmann MW, Kammerle A, Kreienberg R, et al. Certification of breast centres in Germany: proof of concept for a prototypical example of quality assurance in multidisciplinary cancer care. BMC Cancer. 2009:9:228.

20. Heil J, Gondos A, Rauch G, Marme F, Rom J, Golatta M, et al. Outcome analysis of patients with primary breast cancer initially treated at a certified academic breast unit. Breast. 2012;21(3):303-8.

21. Ederer $F$, Axtell $L M$, Cutler $\mathrm{SJ}$. The relative survival rate: a statistical methodology. Natl Cancer Inst Monogr. 1961;6:101-21.

22. De Ronde J, Wessels L, Wesseling J. Molecular subtyping of breast cancer: ready to use? Lancet Oncol. 2010;11(4):306-7.

23. Coates AS, Winer EP, Goldhirsch A, Gelber RD, Gnant M, Piccart-Gebhart M, et al. Tailoring therapies-improving the management of early breast cancer: St GallenInternational Expert Consensus on the Primary Therapy of Early Breast Cancer 2015. Annals Oncol. 2015;26:1533-46.

24. Brouckaert $\mathrm{O}$, Laenen $\mathrm{A}$, Vanderhaegen J, Wildiers $\mathrm{H}$, Leunen $\mathrm{K}$, Amant $\mathrm{F}$, et al. Applying the 2011 St Gallen panel of prognostic markers on a large single hospital cohort of consecutively treated primary operable breast cancers. Annals Oncol. 2012:23(10):2578-84

25. Denkert C, Von Minckwitz G. Reply to Ki67 in breast cancer: a useful prognostic marker! Annals Oncol. 2014;25(2):542-3.

26. Cheang MC, Chia SK, Voduc D, Gao D, Leung S, Snider J, et al. Ki67 index, HER2 status, and prognosis of patients with luminal B breast cancer. J Nat Cancer Inst. 2009;101(10):736-50.

27. Dowsett M, Nielsen TO, A'Hern R, Bartlett J, Coombes RC, Cuzick J, et al. Assessment of Ki67 in breast cancer: recommendations from the International Ki67 in Breast Cancer working group. J Natl Cancer Inst. 2011; 103(22):1656-64

28. Luporsi E, Andre F, Spyratos F, Martin PM, Jacquemier J, Penault-Llorca F, et al. Ki-67: level of evidence and methodological considerations for its role 
in the clinical management of breast cancer: analytical and critical review. Breast Cancer Res Treat. 2012;132(3):895-915.

29. Polley MY, Leung SC, MCShane LM, Gao D, Hugh JC, Mastropasqua MG, et al. An international Ki67 reproducibility study. J Natl Cancer Inst. 2013;105(24):1897-906.

30. Voduc KD, Cheang MC, Tyldesley S, Gelmon K, Nielsen TO, Kennecke H. Breast cancer subtypes and the risk of local and regional relapse. J Clin Oncol Off J Am Soc Clin Oncol. 2010;28(10):1684-91.

31. Dawood S, Hu R, Homes MD, Collins LC, Schnitt SJ, Connolly J, et al. Defining breast cancer prognosis based on molecular phenotypes: results from a large cohort study. Breast Cancer Res Treat. 2011;126(1):185-92.

32. Ferguson NL, Bell J, Heidel R, Lee S, Vanmeter S, Duncan L, et al. Prognostic value of breast cancer subtypes, Ki-67 proliferation index, age, and pathologic tumor characteristics on breast cancer survival in Caucasian women. Breast J. 2013;19(1):22-30.

33. Park S, Koo JS, Kim MS, Park HS, Lee JS, Lee JS, et al. Characteristics and outcomes according to molecular subtypes of breast cancer as classified by a panel of four biomarkers using immunohistochemistry. Breast. 2012;21(1):50-7.

34. Garcia Fernandez A, Gimenez N, Fraile M, Gonzalez S, Chabrera C, Torras M, et al. Survival and clinicopathological characteristics of breast cancer patient according to different tumour subtypes as determined by hormone receptor and Her2 immunohistochemistry. a single institution survey spanning 1998 to 2010. Breast. 2012;21(3):366-73.

35. Puig-Vives M, Sanchez MJ, Sanchez-Cantalejo J, Torrella-Ramos A, Martos C, Ardanaz $\mathrm{E}$, et al. Distribution and prognosis of molecular breast cancer subtypes defined by immunohistochemical biomarkers in a Spanish population-based study. Gynecol Oncol. 2013;130(3):609-14.

36. Minicozzi P, Bella F, Toss A, Giacomin A, Fusco M, Zarcone M, et al. Relative and disease-free survival for breast cancer in relation to subtype: a population-based study. J Cancer Res Clin Oncol. 2013;139(9):1569-77.

37. Mazouni C, Rimareix F, Mathieu MC, Uzan C, Bourgier C, Andre F, et al. Outcome in breast molecular subtypes according to nodal status and surgical procedures. Am J Surg. 2013;205(6):662-7.

38. Kummerow KL, Du L, Penson DF, Shyr Y, Hooks MA. Nationwide trends in mastectomy for early-stage breast cancer. JAMA Surg. 2015;150(1):9-16.

39. Romond EH, Perez EA, Bryant J, Suman VJ, Geyer Jr CE, Davidson NE, et al. Trastuzumab plus adjuvant chemotherapy for operable HER2-positive breast cancer. N Engl J Med. 2005;353(16):1673-84.

40. Gondos A, Jansen L, Heil J, Schneeweiss A, Voogd AC, Frisell J, et al. Time trends in axilla management among early breast cancer patients: Persisting major variation in clinical practice across European centers. Acta Oncol. 2016;55(6):712-9.

\section{Submit your next manuscript to BioMed Central and we will help you at every step:}

- We accept pre-submission inquiries

- Our selector tool helps you to find the most relevant journal

- We provide round the clock customer support

- Convenient online submission

- Thorough peer review

- Inclusion in PubMed and all major indexing services

- Maximum visibility for your research

Submit your manuscript at www.biomedcentral.com/submit

CBiomed Central 